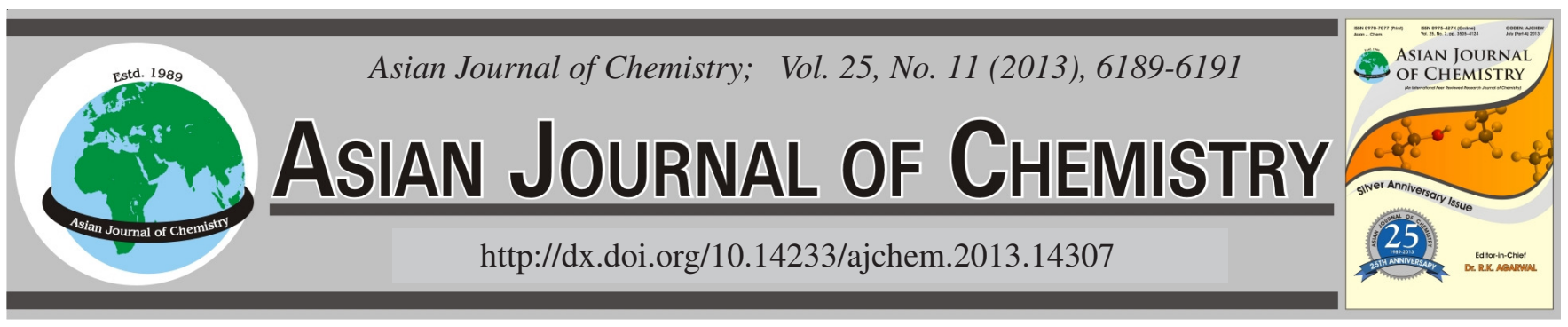

\title{
Nanosized Ferric Hydroxide Catalyzed C-O Cross-Coupling of Phenol and Halides to Generate Phenoxy Ether
}

\author{
Hongbin Sun ${ }^{*}$, Yuanhua Sun, Xiaohua Tian, Yunxia Zhao and Xuan Qi*
}

Department of Chemistry, College of Science, Northeastern University, Shenyang 110819, P.R. China

*Corresponding authors: Tel: +86 24 83671751; E-mail: sunhb@mail.neu.edu.cn; kent.qx@163.com

The iron-based catalyst can effectively catalyze the phenolic hydroxyl C-O bond formation reaction to give the corresponding phenoxy
ethers. The reaction of phenol and methyl chloroacetate, for example, gives phenoxy acetic acid methyl ester in $98 \%$ yield under the
optimal reaction conditions. Among the iron-based catalysts, nanosized ferric hydroxide prepared through sol-gel method gives the best
catalytic activity.
Key Words: Catalysis, Nanosized ferric hydroxide, C-O cross-coupling, Phenoxy ether.

\section{INTRODUCTION}

Phenoxy ethers structures are commonly found in natural products, drugs and other chemical products and they are widely used in the field of medicine and pesticide. The research of phenoxy ethers are concerned subject to the healthcare, plant protection and chemical industry, especially to the creation of new pesticides. For example, phenoxy acid compounds have been used as herbicides for decades and a variety of pesticides such as permethrin and propargites are prepared through the phenoxy ether intermediates. Thus, phenoxy ethers ${ }^{1}$ play a vital role in the production of useful chemicals.

However, the synthesis of the phenoxy ether is not an easy task. Relatively harsh conditions are often required, such as high temperature, high pressure and strong alkaline environment. Synthetic adaptability is not satisfactory for the heat and alkali-sensitive substrate. It is noteworthy that in recent years the use of transition metal catalyzed cross-coupling reaction has become a practical method for $\mathrm{C}-\mathrm{O}$ bond formation which can be used for the synthesis of phenoxy ether. Altman et al. ${ }^{2}$ reported palladium catalytic synthesis of phenoxy ethers in mild conditions with high yield, but the downside is that the complex phosphine ligands were required. Catalytic synthesis of phenoxy ether using cheap catalyst with ligandfree and mild conditions is remaining a challenging job.

In recent years, the iron-catalyzed cross-coupling reaction has been more and more attentive. With the ongoing research, more and more iron catalysts are applied to such catalytic reactions, including $\mathrm{FeCl}_{2}, \mathrm{FeCl}_{3}, \mathrm{Fe}(\mathrm{acac})_{3}, \mathrm{Fe}(\mathrm{OTf})_{2}, \mathrm{Fe}(\mathrm{OAc})_{3}$, etc. $^{3-6}$. They play catalyst roles in the specific cross-coupling reactions. Moreover, in most cases, the iron-based catalysts are consistent with green chemistry for they are efficient, green, non-toxic, environmentally friendly and can be recycled under certain conditions ${ }^{7,8}$. So we plan using ferric based catalyst to develop simple synthetic methods for organic synthesis.

In this paper, we report that the iron catalyst is efficient for the cross-coupling reaction of phenol and halides to generate the corresponding phenoxy ethers. In the initialization of this work, we choose the condensation of phenol and methyl chloroacetate to generate methyl phenoxyacetate as a probe reaction, because this reaction contains a lot of practical information: phenoxyacetic acid ester can be very extensive derivatization, as they can be used for a variety of valuable chemicals. And the reactants and products contain alkalinesensitive ester groups, thus, the condensation reactions under alkaline conditions have side effects that reduce the yield of the target product. For these reasons, although the $\mathrm{C}-\mathrm{Cl}$ bond of chloroacetates is highly reactivated, the yield of product is generally no more than $80 \%$ in the absence of catalyst. Therefore, this reaction can be the identity of the catalytic behaviour for different iron compounds. In a variety of iron compounds, we found that nanosized ferric hydroxide showed the best catalytic effect.

\section{EXPERIMENTAL}

We prepared nano ferric hydroxide using sol-gel method. The hydrosol was generated from boiling ferric solution ${ }^{9,10}$. 
$\mathrm{FeCl}_{3}$ was dissolved in water as the precursor, by adding tartaric acid and alcohol as a dispersing agent, the solution was heated to boiling and the $\mathrm{FeCl}_{3}$ was hydrolyzed, then nano-iron hydroxide sol was obtained. Aging ferric hydroxide sol at $50{ }^{\circ} \mathrm{C}$ for $72 \mathrm{~h}$, the iron hydroxide turned into dry gel. The dry gel was used as a catalyst directly.

Typical procedure for the catalytic reactions: $0.47 \mathrm{~g}$ phenol (5 mmol, 1 eq.), $0.48 \mathrm{~mL}$ methyl chloroacetate $(5.5$ mmol, 1.1 eq.), $26.7 \mathrm{mg}$ nanosized ferric hydroxide $(0.25$ mmol, $5 \mathrm{~mol} \%$ ), $82.7 \mathrm{mg} \mathrm{K} \mathrm{CO}_{3}$ and $572 \mathrm{mg} \mathrm{Na} \mathrm{CO}_{3}$ (1.2 eq. base) and $2 \mathrm{~mL} \mathrm{DMF}$ were added to a sealed tube. The reaction mixture was then heated at $80^{\circ} \mathrm{C}$ for $6 \mathrm{~h}$ under magnetic stirring. After cooling, the mixture was diluted to $50.0 \mathrm{~mL}$ by adding $\mathrm{CH}_{2} \mathrm{Cl}_{2}$. The resulting solution was separated in two parts: $5 \mathrm{~mL}$ was added $100 \mathrm{mg} n$-bromo dodecane as internal standard for GC analysis and others was washed with water and dried over anhydrate sodium sulphate. After the solvent was evaporated, the residue was purified by flash chromatography then phenoxyacetic methyl ester was obtained as colourless oil. The product was identified by ${ }^{1} \mathrm{H}$ NMR and then was used as standard material to correct GC peak area. The calculated GC yield was $98 \%$.

\section{RESULTS AND DISCUSSION}

First, we examine the impact of different iron compounds as catalysts on the reaction. The results are listed in Table-1. Various iron compounds have catalytic activity. Without catalyst the production of phenoxy acetic acid methyl ester was only $25 \%$, while the use of ferric chloride, ferric sulphate as a catalyst, high yield of 80-90\% were obtained, respectively. The catalytic activity of ferric oxide, ferrous sulphate, ferric acetylacetonate is poor to give the moderate yield. Among the ferric catalyst, nanosized ferric hydroxide gave the best results of the reaction. It catalyzed the cross-coupling reaction of phenol and methyl chloroacetate to give methyl phenoxy acetate in almost quantitative yield.

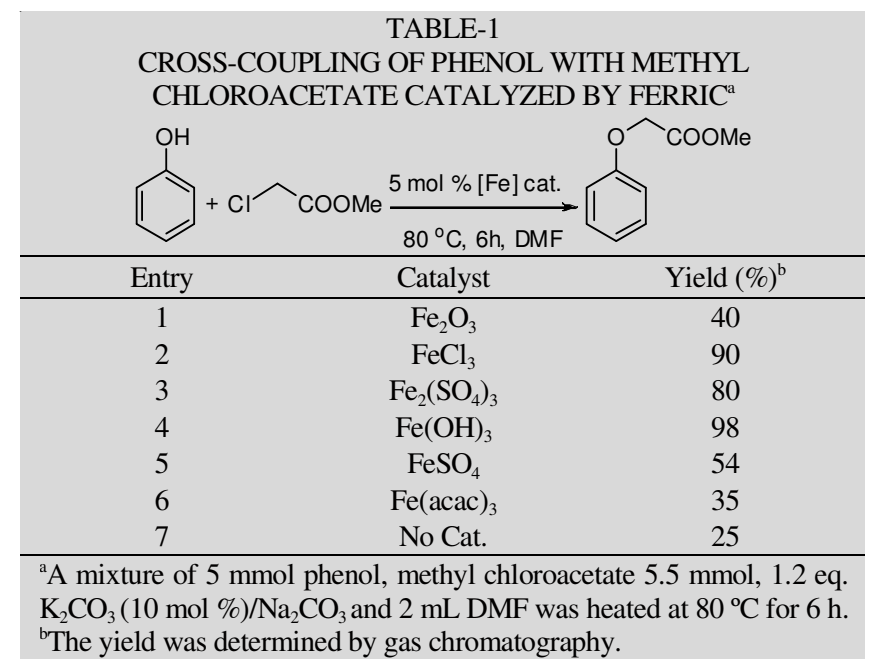

In order to exert nanosized ferric hydroxide's best catalytic activity, the reaction conditions were then optimized. Specifically, we investigated the influence of reaction temperature, reaction time, the addition of alkali and other various factors on the catalytic reaction. The results are summarized in Tables 2 and 3. The addition of alkali is necessary for the
TABLE-2

EFFECTS OF THE DIFFERENT BASES TO THE REACTION ${ }^{a}$

\begin{tabular}{ccc}
$80{ }^{\circ} \mathrm{C}, 6 \mathrm{~h}, \mathrm{DMF}$ \\
\hline Entry & $\mathrm{Base}$ & $\mathrm{GC} \mathrm{Yield}(\%)^{\mathrm{b}}$ \\
\hline 1 & $\mathrm{NaOH}_{3}$ & 0 \\
2 & $\mathrm{Na}_{3} \mathrm{PO}_{4}$ & 35 \\
4 & $\mathrm{Na}_{3} \mathrm{PO}_{4} / \mathrm{K}_{2} \mathrm{CO}_{3}(10 \mathrm{~mol} \%)$ & 86 \\
5 & $\mathrm{~K}_{2} \mathrm{CO}_{3}$ & 98 \\
6 & $\mathrm{Na}_{2} \mathrm{CO}_{3} / \mathrm{K}_{2} \mathrm{CO}_{3}(10 \mathrm{~mol} \%)$ & 90 \\
\hline
\end{tabular}

${ }^{\mathrm{a}} \mathrm{A}$ mixture of $5 \mathrm{mmol}$ phenol, methyl chloroacetate $5.5 \mathrm{mmol}, 1.2 \mathrm{eq}$. $\mathrm{K}_{2} \mathrm{CO}_{3}(10 \mathrm{~mol} \%) / \mathrm{Na}_{2} \mathrm{CO}_{3}$ and $2 \mathrm{~mL} \mathrm{DMF}$ was heated at $80^{\circ} \mathrm{C}$ for $6 \mathrm{~h}$. ${ }^{\mathrm{b}}$ The yield was determined by gas chromatography.

\begin{tabular}{|c|c|c|c|}
\hline \multicolumn{4}{|c|}{$\begin{array}{c}\text { TABLE-3 } \\
\text { EFFECTS OF THE DIFFEREI } \\
\text { TEMPERATURE AND REACTIOI }\end{array}$} \\
\hline & $10 \%$ & $\begin{array}{l}\mathrm{U}_{3}-\mathrm{Na}_{2} \mathrm{CO}_{3}, \\
\mathrm{M}\end{array}$ & coome \\
\hline Entry & Temperature $\left({ }^{\circ} \mathrm{C}\right)$ & Time (h) & GC Yield (\%) \\
\hline 1 & 60 & 6 & 48 \\
\hline 2 & 80 & 6 & 98 \\
\hline 3 & 100 & 6 & 84 \\
\hline 4 & 80 & 1 & 38 \\
\hline 5 & 80 & 3 & 56 \\
\hline 6 & 80 & 6 & 98 \\
\hline 7 & 80 & 12 & 75 \\
\hline
\end{tabular}

equal molar producing of hydrogen halide generated in the reaction. We find that the effect of alkali type is also evident, especially to the yield and selectivity. Strong base such as $\mathrm{NaOH}, \mathrm{Na}_{3} \mathrm{PO}_{4}$ are unfavorable factors for the reactions (Table2 , entry 1,2 ). With the alkaline reducing, the production yield is better.

Both of the pure potassium carbonate and sodium carbonate is acceptable base, but the highest yield was obtained when a mixture base was used. The alkaline of pure sodium carbonate is a little weak and that of pure potassium carbonate is a little strong. So they are not the best choice. While, the mixed base containing $10 \mathrm{~mol} \%$ of potassium carbonate gave the best results. Contrastively, the sodium phosphate is a strong base, when the mixture of sodium phosphate and potassium carbonate was used, lower yield of $46 \%$ was obtained. It is better than pure sodium phosphate but worse than potassium carbonate. It is conformed that the alkaline of adding base is a key factor for the $\mathrm{C}-\mathrm{O}$ cross-coupling, especially when an alkali sensible substrate is employed.

In addition, we also explored the optimal reaction temperature and reaction time (Table-3). Low reaction temperature caused the incomplete conversion of starting material and the side reactions occur while the temperature is too high. To determine the best reaction time is similar to that of the temperature, the reaction should be stopped at a suitable time in order to get best selectivity of target product. The results show that the reaction gives the best result at $80{ }^{\circ} \mathrm{C}$ for $6 \mathrm{~h}$ with $98 \%$ yield. 
In order to develop the nanosized ferric hydroxide catalyzed C-O cross-coupling to a practical synthetic method, a variety of halide was employed to react with phenol to produce corresponding phenoxy ether. Table-4 summarized the products and the yields.

SYNTHESIS OF PHENOXY ETHERS VIA NANOSIZED
FERRIC HYDROXIDE CATALYZED C-O CROSS-
COUPLING OF PHENOL WITH HALIDES

It can be seen through the Table-4, it is feasible for the phenoxy ethers synthesis in optimum conditions. Chloroacetic acid and allyl chloride give the products in high yields of 92 and $80 \%$, respectively. Allyl chloride that is sensible to moisture, but it reacted with phenol to give phenoxy allyl ether smoothly without obvious hydration in the present of carbonate and hydrogen chloride. Even the inactive substrate such as dichloromethane and 1,2-dichloroethane the reactions give the corresponding bis-phenoxy ether in good yield. These results have shown that nanosized ferric hydroxide catalyzed $\mathrm{C}-\mathrm{O}$ cross-coupling is a practical way to synthesize phenoxy ether.

\section{Conclusion}

In summary, nanosized ferric hydroxide prepared through sol-gel method has good catalytic activity for the crosscoupling reaction of phenol and halide to give corresponding phenoxy ether in high yield. This practical means get the advantages of low cost, mild conditions, easy to handle and wide range of adaptability.

\section{ACKNOWLEDGEMENTS}

Financial support from the National Natural Science Foundation of China (21003018) and the Fundamental Research Funds for the Central Universities (N090405007) are gratefully acknowledged.

\section{REFERENCES}

1. D.A. Evans and J.L. Katz, Tetrahedron Lett., 39, 2937 (1998).

2. R.A. Altman, A. Shafir and S.L. Buchwald, J. Org. Chem., 73, 284 (2008).

3. B.J. Li, L. Xu and Z.H. Wu, J. Am. Chem. Soc., 131, 14656 (2009).

4. W. Liu, H. Cao and A. Lei, Angew. Chem. Int. Ed., 49, 2004 (2010).

5. H.W. Lee and S.C. Albert, Tetrahedron Lett., 50, 5868 (2009).

6. K. Swapna, A.V. Kumar and V.P. Reddy, J. Org. Chem., 74, 7514 (2009).

7. N. YoshiKai, A. Mieczkowski and A. Matsumoto, J. Am. Chem. Soc., 132, 5568 (2010).

8. D.M.T. Chan, K.L. Monaco, R.P. Wang and M.P. Winters, Tetrahedron Lett., 39, 2933 (1998).

9. R. Cao, X. Chen and W. Shen, Inorg. Chem. Ind., 43, 6 (2011) (In Chinese).

10. H. Liu, Y. Wei and Y. Sun, J. Mol. Catal. A, 226, 135 (2005). 